\title{
Investment Risk Assessment of Co-generation Based on AHP-FCM
}

\author{
Jinpeng Qiu ${ }^{1, a}$, DongxiaoNiu, ${ }^{2, b}$, Yali Huang ${ }^{3,}$ and Chenshu Shen ${ }^{4, d}$ \\ ${ }^{1,2,3,4}$ School of Business and Management, North China Electric Power University, Beijing, 102206, \\ China.
}

Keywords: Co-generation, Investment, Risk, AHP, FCM

\begin{abstract}
Co-generation central heating is a kind of recognized energy saving and environmental protection technology. In recent years, the technology has been developed rapidly, and it is also the main direction of the future development. This paper constructs a primary index system including 6 indicators of natural risk, social risk, political risk, economic risk, technical risk and other risks, and has formed a secondary index system including 18 indicators. In this paper, we use the analytic hierarchy process to calculate the weight of the evaluation, and combine the fuzzy comprehensive evaluation model to evaluate the investment risk. Examples show that the index system and the AHP-FCM model can be operated and have a good effect.
\end{abstract}

\section{Introduction}

The coal consumption of co-generation of heat and power is $1 / 3$ less than separated generation of heat and power. Co-generation is the main way of central heating, which accounted for more than half of the heat in northern areas. This technology is a distributed energy supply system, which has 20 years of development history in the developed countries.

Therefore, the main direction of the energy saving of the heat source in the central heating system is to develop co-generation and increase the proportion of it. But the variety of uncertain risk often leads to high capital investment. Co-generation investment risk assessment, in order to make better investment decisions, is a practical guide for the plant manager.

\section{Risk evaluation index system for co-generation investment}

Power projects need multilateral cooperation to complete, and any change in a factor will have an impact on the overall situation, so the analysis of the source of investment risk should be multi-angle, multi-faceted, comprehensive and systematic.

(1)Natural risk. The force majeure of the place where the construction project is located, such as the risk of earthquakes, mudslides, typhoons and other harsh natural conditions brought about.

(2) Political risk. The macro-environment of location will have a decisive impact on the project, such as the adjustment of policy, legal environment and political stability, etc.

(3) Social risk. Social risks are mainly related to the development level of the region, the security situation, the environmental protection program and other factors.

(4) Technical risk. Deviations of construction projects design, technical implementation plan and organization design will bring technical risk, such as dereliction of management duty,and other risks, which will affect the duration and quality of the project, and then affect the investment.

(5) Economic risk. The economic risks of construction projects are mainly reflected in the financing plan, the use of funds and the external financial environment.

(6) Other risk. These sources of risk are mainly operational risk, default risk, contract defect risk, mutation of construction conditions and so on.

Based on the above analysis of the risk factors for co-generation investment in technological transformation, the investment risk index system of co-generation as shown in Table 1 below: 
Table 1 investment risk index system of co-generation

\begin{tabular}{|c|c|c|}
\hline Target layer & Standard layer & Index layer \\
\hline \multirow{18}{*}{$\begin{array}{c}\text { Investment Risk } \\
\text { of Co-generation A }\end{array}$} & \multirow{3}{*}{ Natural risk $\mathrm{B}_{1}$} & Coal resource risk $\mathrm{C}_{11}$ \\
\hline & & Water resource risk $C_{12}$ \\
\hline & & Other force majeure $C_{13}$ \\
\hline & \multirow{2}{*}{ Social risk $\mathrm{B}_{2}$} & Fierce market competition $\mathrm{C}_{21}$ \\
\hline & & Social demand outlook $\mathrm{C}_{22}$ \\
\hline & \multirow{2}{*}{ Political risk $\mathrm{B}_{3}$} & Regulatory change risk $\mathrm{C}_{31}$ \\
\hline & & Administrative risk $\mathrm{C}_{32}$ \\
\hline & \multirow{4}{*}{ Economic risk $\mathrm{B}_{4}$} & Risk of Interest rate change $\mathrm{C}_{41}$ \\
\hline & & Risk of exchange rate change $\mathrm{C}_{42}$ \\
\hline & & Price, labor costs rise $\mathrm{C}_{43}$ \\
\hline & & Financial riskC $\mathrm{C}_{44}$ \\
\hline & \multirow{4}{*}{ Technical risk $\mathrm{B}_{5}$} & Construction scheme change $\mathrm{C}_{51}$ \\
\hline & & Quality level requirements $C_{52}$ \\
\hline & & Quality of design $C_{53}$ \\
\hline & & The complexity of Technology $\mathrm{C}_{54}$ \\
\hline & \multirow{3}{*}{ Other risk $\mathrm{B}_{6}$} & Management level $\mathrm{C}_{61}$ \\
\hline & & Contract risk $\mathrm{C}_{62}$ \\
\hline & & Project control risk $\mathrm{C}_{63}$ \\
\hline
\end{tabular}

\section{AHP-FCM Risk Assessment Model}

AHP-FCM evaluation model has the following steps:

(1) Determine the factors of evaluation object

P numbers of evaluation index altogether, $u=\left\{u_{1}, u_{2}, \cdots \cdots, u_{p}\right\}$.

(2) Determine the level of comments on the domain

$v=\left\{v_{1}, v_{2}, \cdots \cdots, v_{p}\right\}$, which indicates level set. Each level may correspond to a fuzzy subset.

(3) Establishing fuzzy relational matrix

After constructing the fuzzy subsets, each factor $u_{i}(i=1,2, \cdots \cdots, p)$ of the evaluated object is to be quantified, namely, the membership degree $\left(R \mid u_{i}\right)$ of the fuzzy subsets is obtained by the single factor, and then the fuzzy relational matrix is obtained.

$$
R=\left[\begin{array}{cc}
R \mid & u_{1} \\
R \mid & u_{2} \\
\cdots & \\
R \mid & u_{p}
\end{array}\right]=\left[\begin{array}{cccc}
r_{11} & r_{12} & \cdots & r_{1 m} \\
r_{21} & r_{22} & \cdots & r_{2 m} \\
\cdots & \cdots & \cdots & \cdots \\
r_{p 1} & r_{p 2} & \cdots & r_{p m}
\end{array}\right]_{p . m}
$$

Element $r_{i j}$ in the NO.i row and NO.j column of the matrix, which indicates the membership degree of fuzzy subsets, evaluated by the factor $u_{i}$ on the $v_{j}$ level. The performance of the evaluated object in a certain factor $u_{i}$ is characterized by fuzzy vector $\left(R \mid u_{i}\right)=\left(r_{i 1}, r_{i 2}, \cdots \cdots, r_{i m}\right)$.

(4) Weight vector of evaluation factors

Seeking the weight is the key of comprehensive evaluation. Analytic hierarchy process is an effective method to determine weight coefficient. The method is based on the objective reality of fuzzy judgment. In this method, the relative importance of each level is given a quantitative representation, and then use the mathematical method to determine the relative importance of all elements of the order of weight coefficient.

In fuzzy comprehensive evaluation, the weight vector of the evaluation factor is determined: $A=\left(a_{1}, a_{2}, \cdots \cdots, a_{p}\right)$. The element $a_{i}$ in the weight vector $\mathrm{A}$ is essentially the membership degree of the fuzzy subsets of factor $u_{i}$. In this paper, we use the analytic hierarchy process to determine 
the relative order of importance of the evaluation index, and then determine the weight coefficient, and normalize before the synthesis. That is $\sum_{i=1}^{p} a_{i}=1, a_{i} \geq 0, i=1,2, \cdots \cdots, n$.

(5) Synthetic fuzzy comprehensive evaluation result vector

By using appropriate operator, the weight vector and the fuzzy relation matrix of the evaluated object are synthesized and the fuzzy comprehensive evaluation results vectors are obtained. Which is

$$
A \circ R=\left(a_{1}, a_{2}, \cdots \cdots, a_{p}\right)\left[\begin{array}{cccc}
r_{11} & r_{12} & \cdots & r_{1 m} \\
r_{21} & r_{22} & \cdots & r_{2 m} \\
\cdots & \cdots & \cdots & \cdots \\
r_{p 1} & r_{p 2} & \cdots & r_{p m}
\end{array}\right]=\left(b_{1}, b_{2}, \cdots \cdots, b_{m}\right)=B
$$

While $b_{j}$ is obtained by the weight vector multiply the NO.j column operations of fuzzy relational matrix, it represents the membership degree of the fuzzy subset on the $v_{j}$ level in the whole.

\section{Empirical Analysis}

Assignment vector is $C=\left\{c_{1}, c_{2}, c_{3}, c_{4}, c_{5}\right\}=\{1,2,3,4,5\}$, which respectively correspond to the evaluation set vector \{the risk is small, with less risk, the risk in general, a greater risk, high risk\}. According to the formula $V=B \cdot C^{T}$, comprehensive evaluation index value and each individual value can be calculated .

In this section, the comprehensive evaluation of the investment risk of the co-generation project is carried out by using the fuzzy evaluation model above. In order to obtain objective and authoritative evaluation results, eight experts in the relevant fields are responsible for scoring the fuzzy membership degree of how each factor of evaluation index relative to each factor in the evaluation collection. By statistical calculation, the weight of the first index is obtained:

Table 2 weight of the first class index

\begin{tabular}{cccccccc}
\hline A & B1 & B2 & B3 & B4 & B5 & B6 & W \\
\hline B1 & 1 & $1 / 9$ & $1 / 3$ & $1 / 6$ & $1 / 9$ & $1 / 2$ & 0.0269 \\
B2 & 9 & 1 & 5 & $1 / 6$ & $1 / 8$ & 3 & 0.1338 \\
B3 & 3 & $1 / 5$ & 1 & $1 / 4$ & $1 / 6$ & 3 & 0.0644 \\
B4 & 6 & 6 & 4 & 1 & 2 & 7 & 0.3757 \\
B5 & 9 & 8 & 6 & $1 / 2$ & 1 & 6 & 0.3597 \\
B6 & 2 & $1 / 3$ & $1 / 3$ & $1 / 7$ & $1 / 6$ & 1 & 0.0395 \\
\hline
\end{tabular}

After the weight calculation, the consistency of the judgment matrix needs to be tested, and the calculation is obtained:

$$
\lambda_{\max }=6.013, C I=0.0026, R I=1.2482
$$

Because $C R=0.002<0.1$, the consistency check of the judgment matrix is satisfied.

Taking the first level index as the criterion, according to the same method as described above, the weight of the secondary indicators can be calculated. According to the previous work, the weight vector of the first level indicator is $\mathrm{W}$, and the secondary level evaluation vector is obtained.

$$
B=W R=\{0.415,0.214,0.142,0.125,0.104\}
$$

According to the formula $V=B \cdot C^{T}$, investment risk value can be calculated. $V=B \cdot C^{T}=2.289$. Therefore, investment risk of the project is small, and in line with the actual situation faced by the owner. 


\section{Summary}

In this paper, a comprehensive evaluation index system of the investment risk is constructed, which has some versatility in investment risk assessment. This article combined the AHP and fuzzy comprehensive evaluation model. Based on expert knowledge and subjective experience, AHP uses analytic hierarchy process to determine the weight of each index, and its strict mathematical method will reduce the level of subjectivity. In the case analysis, the use of fuzzy comprehensive evaluation of project investment risk is basically consistent with the actual risk situation, reflecting the application of the index system and fuzzy comprehensive evaluation model in the evaluation of co-generation investment risk.

\section{References}

[1] Wetangula G, Snorrason S S. Ecological risk assessment of Nesjavellir co-generation plant waste water disposal on Lake Thingvallavatn in SW-Iceland[J]. Proceedings of Igc, 2003.

[2] Akikur R K, Saidur R, Ping H W, et al. Performance analysis of a co-generation system using solar energy and SOFC technology[J]. Energy Conversion \& Management, 2014, 79(2):415-430.

[3] Cormos A M, Cormos C C. Investigation of hydrogen and power co-generation based on direct coal chemical looping systems[J]. International Journal of Hydrogen Energy, 2014, 39(5):2067-2077. 